\title{
Separation of 1,3-propanediol from Aqueous Solutions by Ion Exchange Chromatography
}

\author{
Beata Rukowicz, Ireneusz Miesiąc, Krzysztof Alejski \\ Poznan University of Technology, Institute of Technology and Chemical Engineering, pl. M. Skłodowskiej- \\ -Curie 2, 60-965 Poznan, Poland, e-mail: beata.rukowicz@doctorate.put.poznan.pl
}

\begin{abstract}
1,3-propanediol is a promising monomer with many applications and can be produced by bioconversion of renewable resources. The separation of this product from fermentation broth is a difficult task. In this work, the application of cation exchange resin for the separation of 1,3-propanediol from model aqueous solution was examined. The best effect of separation of 1,3-propanediol from glycerol using sorption method was obtained for $\mathrm{H}^{+}$resin form, although the observed partition coefficient of 1,3-propanediol was low. On the basis of the results of the sorption of 1,3-propanediol, the ionic forms of the resin were selected and used in the next experiments $\left(\mathrm{H}^{+}, \mathrm{Ca}^{2+}, \mathrm{Ag}^{+}\right.$, $\left.\mathrm{Na}^{+}, \mathrm{Pb}^{2+}, \mathrm{Zn}^{2+}\right)$. The best results in ion exchange chromatography were obtained for cation exchange resin in $\mathrm{H}^{+}$and $\mathrm{Ca}^{2+}$ form. The use of smaller particle size of resin and a longer length of the column allows to obtain better separation of mixtures.
\end{abstract}

Keywords: 1,3-propanediol, glycerol, fermentation, sorption, ion exchange chromatography.

\section{INTRODUCTION}

According to the strategy of the European Union, the policy of the members of EU should lead to an increase in the share of energy produced from renewable sources. One of renewable energy sources is biodiesel, which is a mixture of fatty acids methyl esters. In the production of $100 \mathrm{~kg}$ of biodiesel, 10-20 kg of waste glycerol with a purity of $55-90 \%$ is obtained. The growth of biofuel production generates an excess of glycerol in the global market. Therefore, waste glycerol processing is necessary to increase the profitability of biodiesel production ${ }^{\mathbf{1}, 2}$.

One of the potential solutions is to use glycerol as a carbon source in bioconversion to 1,3-propanediol. Therefore, the development of the methods of separation and purification is very important for microbiological production $^{3}$.

Several methods for the separation of 1,3-propanediol from fermentation broth have been reported. This methods mainly include distillation, pervaporation, ion exchange chromatography, membrane filtration, solvent extraction, and reactive extraction ${ }^{3}$. The use of chromatographic technique for the purification of 1,3-propanediol has been regarded as a promising and effective method. Hilaly and Thomas ${ }^{4}$ and Roturier et al. ${ }^{5}$ used a strong cation exchange resin of polystyrene sulfonated type in the various form to separate of 1,3-propanediol from glycerol and glucose. Separation of these mixtures with the use of chromatographic method was also presented by Wilkins and Lowe ${ }^{6}$ and Adkesson et al. ${ }^{7}$. Cho et al. ${ }^{8}$ and Barski et al. ${ }^{9}$ examined chromatographic columns packed with silica gel resins using methanol and ethanol as a mobile phase. Adsorption on zeolites and polymeric resins has been proposed for 1,3-propanediol separation ${ }^{10,11}$. The possibility of using adsorption is limited due to the low capacity of sorbents.

In this work, the application of the cation exchange resins for the separation of 1,3-propanediol from the aqueous solution was examined. Model aqueous mixtures with a composition appropriate to the fermentation broth were used for investigations.

\section{EXPERIMENTAL}

\section{Experimental procedures}

A polystyrene sulfonate type cation exchange resin, cross-linked with divinylbenzene $(8 \%)$ produced by Spectrum was used for investigations. Two different particle sizes: $40-75 \mu \mathrm{m}$ (200-400 mesh) and 75-150 $\mu \mathrm{m}$ (100-200 mesh) were used. The effectiveness for separation were examined for various ionic forms of the bed $\left(\mathrm{H}^{+}, \mathrm{Ca}^{2+}, \mathrm{Ag}^{+}, \mathrm{Na}^{+}, \mathrm{Pb}^{2+}, \mathrm{Zn}^{2+}, \mathrm{Li}^{+}, \mathrm{Co}^{2+}\right.$, $\left.\mathrm{Cu}^{2+}\right)$. Aqueous solutions of suitable salts were used to convert the original $\mathrm{H}^{+}$form into particular ion form. $5 \%$ salt water solution was passed through the resin for 30 minutes. The volume of aqueous salt solutions exceeded twice the total exchange capacity of resin $(1.7 \mathrm{meq} / \mathrm{ml})$.

The concentration of 1,3-propanediol, glycerol, and 2,3-butanediol was determined by HPLC with refractive index detector and $2.5 \mathrm{mM} \mathrm{H}_{2} \mathrm{SO}_{4}$ as the mobile phase. Analysis was performed on a Hypersil ODS column (100 x $4.6 \mathrm{~mm}$, Agilent) and Rezex ROA-Organic Acid column ( $250 \times 4.6 \mathrm{~mm}$, Phenomenex).

\section{Sorption on resin}

The experiment was carried out to examine the effectiveness of the sorption of 1,3-propanediol from the aqueous solution. Model aqueous mixtures containing $50 \mathrm{~g} / \mathrm{L} 1,3$-propanediol and $50 \mathrm{~g} / \mathrm{L}$ glycerol were used. Polypropylene columns with a length of $60 \mathrm{~mm}$ and an inner diameter of $5 \mathrm{~mm}$ were packed with a suitable resin in appropriate ionic form (particle size $40-75 \mu \mathrm{m}$, volume $1.2 \mathrm{~mL}$ ). A volume of $5 \mathrm{~mL}$ of aqueous solution was fed into the top of the column at a flow rate of $0.4 \mathrm{~mL} / \mathrm{min}$. Then, the desorption process was carried out with deionized water as an eluent and the obtained fractions $(0.5 \mathrm{~mL})$ were analyzed using HPLC.

\section{Chromatographic process}

The chromatographic separation was carried out at room temperature using a polypropylene column with a length of $25-50 \mathrm{~cm}$ and a diameter of 5-20 mm (bed volume 4.9-116 mL). The chromatographic system consists of a pump, column and RI detector and was con- 
nected to the LP-chrom software (Lipopharm). A set of experiments were carried out for one component solution and for aqueous mixtures containing 1,3-propanediol, glycerol and 2,3-butanediol. Studies on the selection of the selective stationary phase were conducted for the resin with a particle size $40-75 \mu \mathrm{m}$. On the basis of the obtained results, the ionic forms of the resin were selected and used in further experiments $\left(\mathrm{H}^{+}, \mathrm{Ca}^{2+}, \mathrm{Ag}^{+}\right.$, $\left.\mathrm{Na}^{+}, \mathrm{Pb}^{2+}, \mathrm{Zn}^{2+}\right)$. The effect of the column length and bead size of resin on the separation of 1,3-propanediol was also examined.

\section{RESULTS AND DISCUSSION}

\section{Sorption selectivity}

Different ionic form of cation exchange resins were tested for the sorption of 1,3-propanediol and glycerol. The selectivity was defined as the ratio of the concentration of 1,3-propanediol to concentration of glycerol.

Sorption selectivity of 1,3-propanediol and glycerol for the $\mathrm{Li}^{+}, \mathrm{Co}^{2+}$, and $\mathrm{Zn}^{2+}$ resins was lower than 1.0. These resin forms cannot be used for the separation of 1,3-propanediol from fermentation broth using sorption methods. The higher affinity of glycerol to the resin was observed for the $\mathrm{Pb}^{2+}, \mathrm{Ag}^{+}$, and $\mathrm{Ca}^{2+}$ form. Only for beds with the ionic forms: $\mathrm{H}^{+}, \mathrm{Cu}^{2+}$, and $\mathrm{Na}^{+}$, the selectivity for 1,3-propanediol over glycerol was higher than 1.0. The best results was obtained for the $\mathrm{H}^{+}$form which allows the effective recovery of 1,3-propanediol from aqueous solution.

Unfortunately, the direct sorption of polyols from the fermentation broth is limited due to the low efficiency of the process. Therefore, the separation of 1,3-propanediol from aqueous solutions was carried out using chromatographic techniques.

\section{Ion exchange chromatography}

In this preparative technique, the amounts of substances introduced onto column are much bigger than in analytical scale. The column works in overloading mode, feed volumes are comparable with the column volume and the bead sizes are substantially larger. As a result, only partial separation of feed components is possible and the cross-contaminated fractions have to be recycled.

In the first step, the single component solutions were passed through the bed to determine the position of the elution curves. In the next step the aqueous solutions of two and three components were fed into the column. The results were obtained for resins with fine particle size $(40-75 \mu \mathrm{m})$ using a moderate flow rate of $3 \mathrm{~h}^{-1}$, and for small column loading (feed $=0.02 \mathrm{~V}_{\mathrm{B}}$ ).

Based on the results for the resin in $\mathrm{Na}^{+}, \mathrm{Zn}^{2+}$, and $\mathrm{Ag}^{+}$forms it can be concluded that they are not convenient for the separation of 1,3-propanediol from the fermentation broth using chromatography. Figure 1, 2 and 3 show the elution curves obtained for the 50 $\mathrm{g} / \mathrm{L}$ one-component solutions. Then, the binary aqueous solutions containing $50 \mathrm{~g} / \mathrm{L}$ 1,3-propanediol and $50 \mathrm{~g} / \mathrm{L}$ glycerol or 2,3-butanediol were passed through the column $\left(\mathrm{Na}^{+}, \mathrm{Zn}^{2+}\right.$, and $\left.\mathrm{Ag}^{+}\right)$. In each case the separation was not achieved.
Further experiments were carried out for the $\mathrm{Pb}^{2+}$ form. The separation of 1,3-propanediol from the aqueous so-

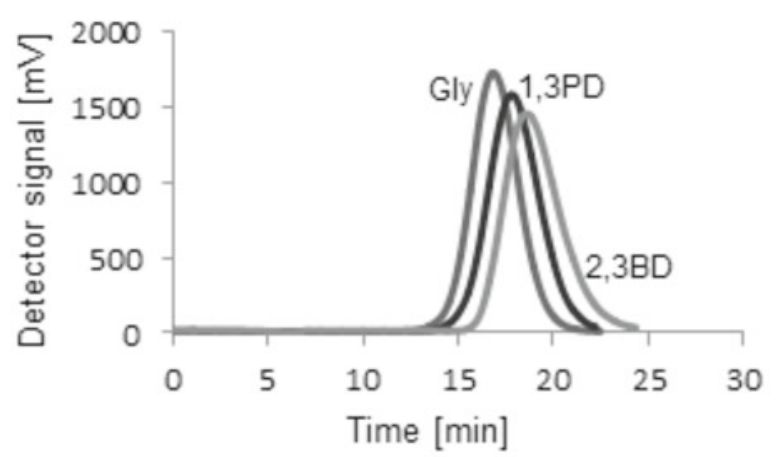

Figure 1. Elution curves for $\mathrm{Na}^{+}$form (particle size: 40-75 $\mu \mathrm{m}$, flow rate: $3 \mathrm{~h}^{-1}$, column length: $25 \mathrm{~cm}$ )

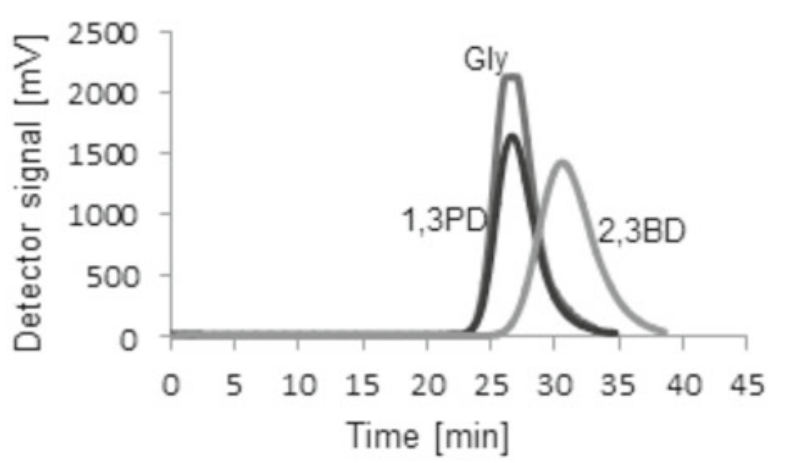

Figure 2. Elution curves for $\mathrm{Ag}^{+}$form (particle size: 40-75 $\mu \mathrm{m}$, flow rate: $3 \mathrm{~h}^{-1}$, column length: $25 \mathrm{~cm}$ )

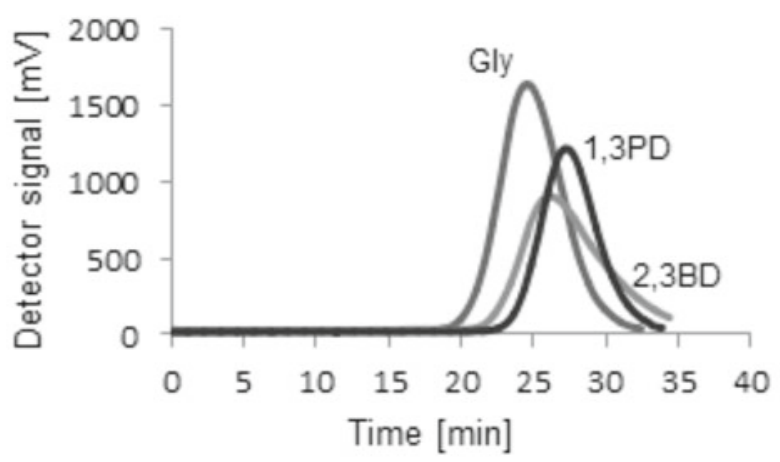

Figure 3. Elution curves for $\mathrm{Zn}^{2+}$ form (particle size: $40-75 \mu \mathrm{m}$, flow rate: $3 \mathrm{~h}^{-1}$, column length: $25 \mathrm{~cm}$ )

lution is very similar to the results obtained for the $\mathrm{Ca}^{2+}$ form. In both cases, the separation of 1,3-propanediol from both glycerol and 2,3-butanediol was obtained, and further study was carried out with the $\mathrm{Ca}^{2+}$ resin. Figures 4 and 5 present the elution curves obtained for different flow rates $\left(3 \mathrm{~h}^{-1}\right.$ and $\left.4 \mathrm{~h}^{-1}\right)$ in one compound solutions $(50 \mathrm{~g} / \mathrm{L})$. Based on the obtained results it can be concluded that the eluent flow rate has a significant effect on the separation of the mixture.

Binary and ternary mixtures (containing $50 \mathrm{~g} / \mathrm{L}$ 1,3-propanediol, $50 \mathrm{~g} / \mathrm{L}$ glycerol, and $50 \mathrm{~g} / \mathrm{L}$ 2,3-butanediol) were separated with a flow rate of $3 \mathrm{~h}^{-1}$. The results of the research are presented in Figure 4 and 5. The peaks in the elution curves were relatively well separated, which indicates the ability of $\mathrm{Ca}^{2+}$ form for the separation of 1,3-propanediol using chromatography. 
The best separation of 1,3-propanediol from glycerol, using both sorption and chromatographic methods was

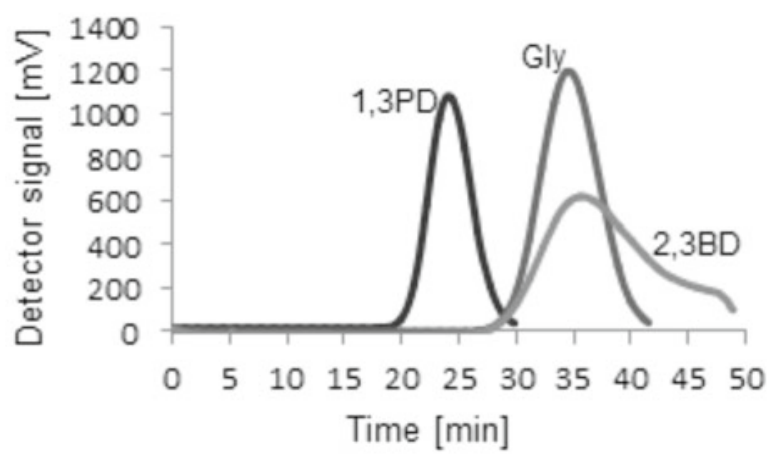

Figure 4. Elution curves for $\mathrm{Ca}^{2+}$ form (particle size: $40-75 \mu \mathrm{m}$, flow rate: $3 \mathrm{~h}^{-1}$, column length: $25 \mathrm{~cm}$ )

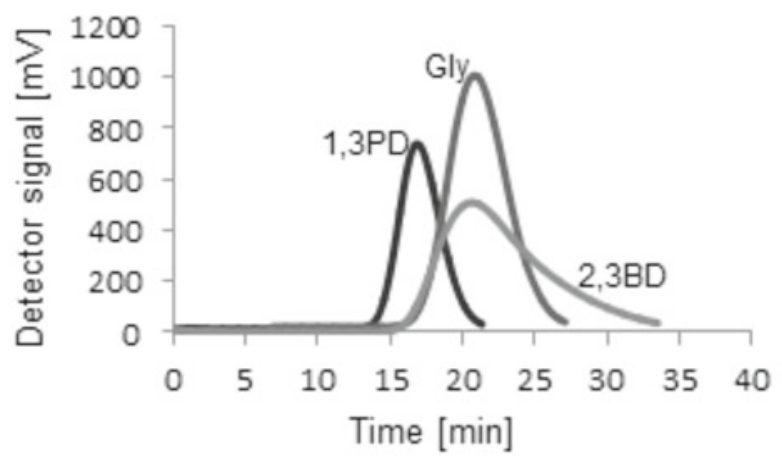

Figure 5. Elution curves for $\mathrm{Ca}^{2+}$ form (particle size: $40-75 \mu \mathrm{m}$, flow rate: $4 \mathrm{~h}^{-1}$, column length: $25 \mathrm{~cm}$ )

obtained for $\mathrm{H}^{+}$resin form. Single compound solutions containing $50 \mathrm{~g} / \mathrm{L}$ of 1,3-propanediol, glycerol or 2,3-butanediol were passed through the column (length $25 \mathrm{~cm}$ ) (Fig. 6). Then, the study was repeated for aqueous binary mixtures containing $50 \mathrm{~g} / \mathrm{L}$ 1,3-propanediol and $50 \mathrm{~g} / \mathrm{L}$ glycerol or 2,3-butanediol. For the 1,3-propanediol-glycerol partially separated peaks were obtained (Fig. 7), whereas for the mixture containing 1,3-propanediol and 2,3-butanediol separation was not achieved. The $\mathrm{H}^{+}$form allows the efficient separation of 1,3-propanediol from glycerol, but no separation occurs for 1,3-propanediol and 2,3-butanediol.

The weakest resolution of the three components and the smallest retention times were obtained on the $\mathrm{Na}^{+}$

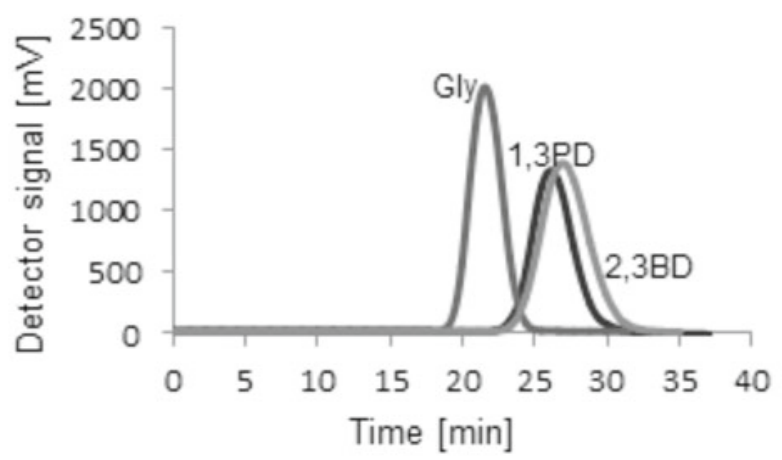

Figure 6. Elution curves for $\mathrm{H}^{+}$form (particle size: $40-75 \mu \mathrm{m}$, flow rate: $3 \mathrm{~h}^{-1}$, column length: $25 \mathrm{~cm}$ )

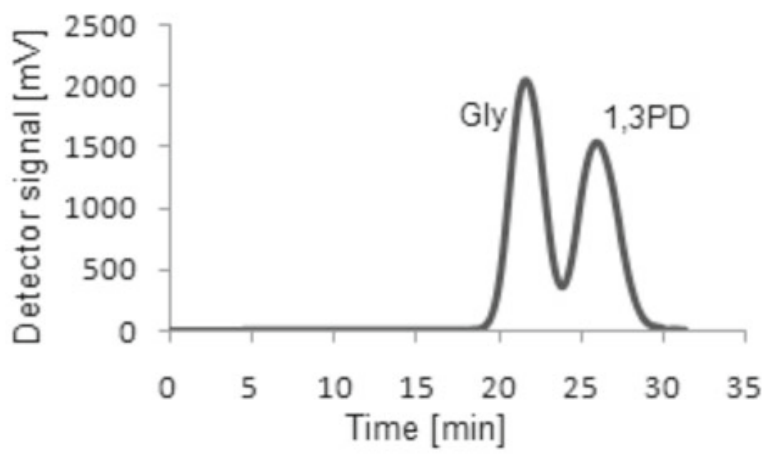

Figure 7. Elution curve for $\mathrm{H}^{+}$form (particle size: $40-75 \mu \mathrm{m}$, flow rate: $3 \mathrm{~h}^{-1}$, column length: $25 \mathrm{~cm}$ )

form of resin. The increase in retention time agrees with the increasing hydrophobicity of component. For $\mathrm{Zn}^{2+}$ form the retention time increases in the same order, but the resolution of glycerol and both other components are better. A similar effect was obtained for the original $\mathrm{H}^{+}$resin, but the peaks were slimmer and higher i.e. the column effectiveness was better (Fig. 6). All the tree investigated components are hydrophilic and interact with hydrophilic resin core which contains ca. $50 \%$ water. The observed separation may be a result of little differences in water content for different ionic form. On the other hand, the internal water can be of different activity which enables a better sorption of compounds more hydrophobic. The most hydrophilic ionic form is $\mathrm{Na}^{+}$ (highly hydrated) which exhibits the shortest retention times and lowest selectivity of separation. The $\mathrm{H}^{+}$and $\mathrm{Zn}^{2+}$ forms are probably more hydrophobic due to lower degree of hydration, i.e. more hydrophobic interactions. As a result, the retention of all components, especially more hydrophobic of 1,3-propanediol and 2,3-butanediol, are higher.

In the bioconversion of glycerol to 1,3-propanediol the fermentation broth is obtained with the composition reflecting the process conditions. Several studies in the literature indicate that residual glycerol is present in the broth. The best parameters for the separation of 1,3-propanediol from glycerol were obtained using a $\mathrm{H}^{+}$ form, therefore further investigations were performed using this form of resin for the one-compound solutions and for the aqueous mixtures containing 1,3-propanediol and glycerol. The effects of the flow rate, column length, and the bead size of the resin were examined.

The results of the separation of a solution containing $50 \mathrm{~g} / \mathrm{L} \mathrm{1,3-propanediol} \mathrm{and} 50 \mathrm{~g} / \mathrm{L}$ glycerol with a column length of $50 \mathrm{~cm}$ are shown in Figure 8 . Comparing with the results shown in Figure 7 (column length $25 \mathrm{~cm}$ ), it can be concluded that increasing the length of the column substantially enhances the efficiency of separation i.e. lengthening the column twice allowed a complete separation of peaks.

In the last stage of the study, $\mathrm{H}^{+}$form with a particle size $75-150 \mu \mathrm{m}$ was used to determine the influence of the particle size on the effect of separation. The results for the solutions containing $50 \mathrm{~g} / \mathrm{L} \mathrm{1,3-propanediol} \mathrm{or}$ glycerol are shown in Figure 9. The use of smaller particle size allows to obtain better separation of mixtures.

In order to increase the efficiency of separation in chosen conditions a larger column with dimensions 


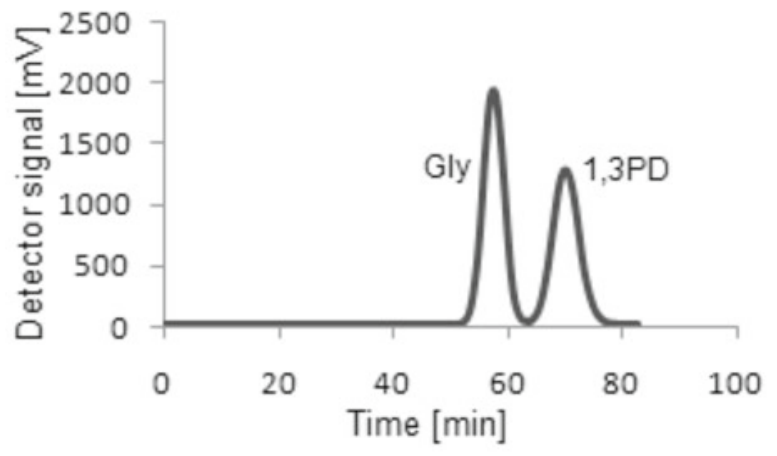

Figure 8. Elution curve for $\mathrm{H}^{+}$form (particle size: 40-75 $\mu \mathrm{m}$, flow rate: $1.3 \mathrm{~h}^{-1}$, column length: $50 \mathrm{~cm}$ )

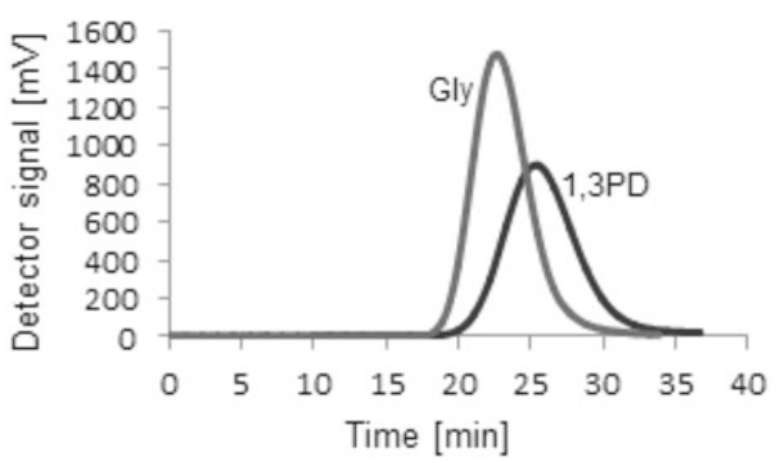

Figure 9. Elution curves for $\mathrm{H}^{+}$form (particle size: $75-150 \mu \mathrm{m}$, flow rate: $3.5 \mathrm{~h}^{-1}$, column length: $25 \mathrm{~cm}$ )

$2 \times 37 \mathrm{~cm}$ packed with resin in $\mathrm{H}^{+}$form $(75-150 \mu \mathrm{m})$ was used. Investigations were conducted with two solutions at different flow rates: an aqueous solution of 50 $\mathrm{g} / \mathrm{L}$ 1,3-propanediol and $25 \mathrm{~g} / \mathrm{L}$ glycerol at a flow rate of $2.4 \mathrm{~h}^{-1}$, and a solution containing $50 \mathrm{~g} / \mathrm{L} 1,3$-propanediol, $50 \mathrm{~g} / \mathrm{L}$ glycerol and $50 \mathrm{~g} / \mathrm{L} 2,3$-butanediol at a flow rate of $0.8 \mathrm{~h}^{-1}$. The concentration of the components of the obtained fractions was determined using HPLC. The results are shown in Figure 10. and 11.

It can be concluded that in the investigated region $\left(0.8-2.4 \mathrm{~h}^{-1}\right)$ the flow rate does not affect the separa-

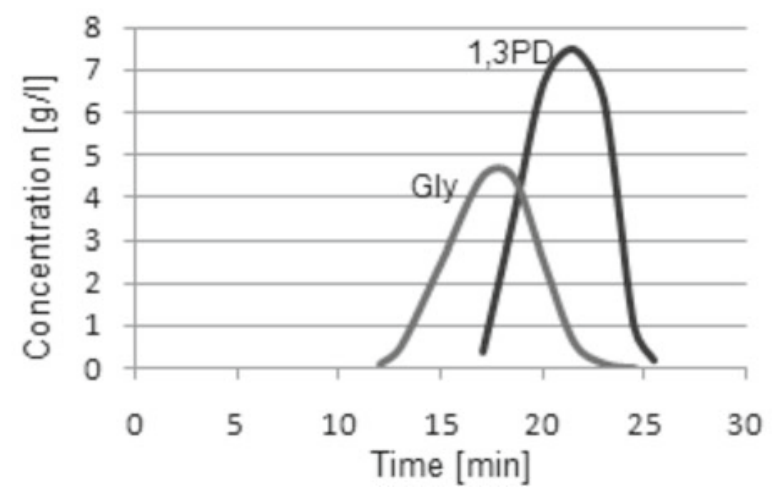

Figure 10. Elution curves for $\mathrm{H}^{+}$form (particle size: $75-150 \mu \mathrm{m}$, flow rate: $2.4 \mathrm{~h}^{-1}$, column length: $37 \mathrm{~cm}$, column loading $0.04 \mathrm{VB})$

tion efficiency (see symmetrical shape of the peaks), i.e. more effective is the higher flow rate. From a practical point of view the column loading has to be as high as column dead volume $0.35 \mathrm{~V}_{\mathrm{B}}$. Then the maximal elute concentration reaches the feed value. However, in all

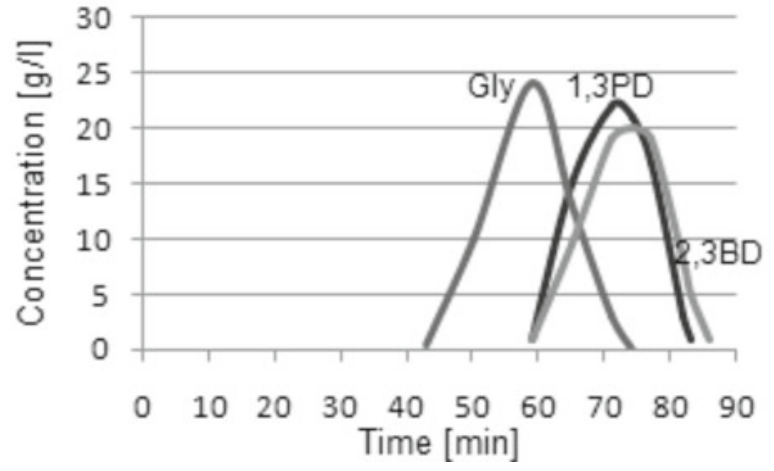

Figure 11. Elution curves for $\mathrm{H}^{+}$form (particle size: 75-150 $\mu \mathrm{m}$, flow rate: $0.8 \mathrm{~h}^{-1}$, column length: $37 \mathrm{~cm}$, column loading $0.1 \mathrm{VB})$

the cases the obtained fraction of elude solution is more than twice diluted owing to separation principle.

Based on the research it can be concluded that the chromatographic method enables efficient separation of 1,3-propanediol from the fermentation broth. The downstream processing of biologically produced 1,3 -propanediol can be divided into three stages. In the first stage the ion exclusion is used for the separation of organic and inorganic salts from the broth. The second stage is the removal of nonionic impurities using ion exchange chromatography. Depending on the composition of the broth, cation exchange resin in the form of $\mathrm{H}^{+}$or $\mathrm{Ca}^{2+}$ should be applied for the separation process. In the last step the vacuum distillation should be used to remove the water and to final purification of 1,3-PD.

\section{CONCLUSIONS}

The aim of the presented studies on the separation of 1,3-propanediol using chromatography was to select the most appropriate bed. Based on the performed experiments, it was found that in the process of the separation of 1,3-propanediol from the aqueous solution $\mathrm{H}^{+}$or $\mathrm{Ca}^{2+}$ resin form should be applied. The possibility of using water as the mobile phase allows to eliminate the use of organic solvents. The results of separation of multicomponent mixtures provides a good basis to further research on the semi-technical scale.

\section{ACKNOWLEDGMENT}

This research was supported by the project „Biotechnological conversion of glycerol to polyols and dicarboxylic acids", implemented within the Operational Programme - Innovative Economy, 2007-2013, co-financed by the European Union. Contract: POIG 01.01.02-00-074/09.

\section{LITERATURE CITED}

1. Posada, J.A., Rincon, L.E. \& Cardona, C.A. (2012). Design and analysis of biorefineries based on raw glycerol: Addressing the glycerol problem. Bioresource Technol. 111, 282-293. DOI: 10.1016/j.biortech.2012.01.151.

2. Xiu, Z.L. \& Zeng, A.P. (2008). Present state and perspective of downstream processing of biologically produced 1,3-propanediol and 2,3-butanediol. Appl. Microbiol. Biotechnol. 78, 917-926. DOI: 10.1007/s00253-008-1387-4.

3. Anand, P., Saxena, R.K. \& Marwah, R.G. (2011). A novel downstream process for 1,3-propanediol from glycerol-based 
fermentation. Appl Microbiol Biotechnol 90, 1267-1276. DOI: 10.1007/s00253-011-3161-2.

4. Hilaly, A.K. \& Binder, T.P. (2002). U.S. Patent No. $6,479,716$.

5. Roturier, J.M., Fouache, C. \& Berghmans, E. (2002). U.S. Patent No. 6,428,992.

6. Wilkins, A.E. \& Lowe, D.J. (2004). U.S. Patent No. $6,812,000$.

7. Adkesson, D.M., Alsop, A.W., Ames, T.T., Chu, L.A., Disney, J.M., Dravis, B.C., Fitzgibbon, P., Gaddy, J.M., Gallagher, F.G., Lehnhardt, W.F., Lievense, J.C., Luyben, M.L., Seapan, M., Trotter, R.E., Wenndt, G.M. \& Yu, E.K. (2005). U.S. Patent No. 2005/0069997.

8. Cho, M.H., Joen, S.I., Pyo, S.H., Mun, S. \& Kim, J.H. (2006). A novel separation and purification process for 1,3-propanediol. Process Biochem. 41, 739-744. DOI: 10.1016/j. procbio.2005.11.013.

9. Barski, P., Kowalczyk, J., Lindstaedt, A., Puzewicz-Barska, J. \& Witt, D. (2012). Evaluation of solid phase extraction for downstream separation of propane-1,3-diol and butan-1-ol from fermentation broth. Process Biochem. 47, 1005-1010. DOI: 10.1016/j.procbio.2012.03.013.

10. Corbin, D.R. \& Norton, T. (2003). U.S. Patent No. $6,603,048$.

11. Luerruk, W., Shotipruk, A., Tantayakom, V., Prasitchoke, P., Muangnapoh, C. (2009). Adsorption of 1,3-propanediol from synthetic mixture using polymeric resin as adsorbents. Front. Chem. Eng. China 3(1), 52-57. DOI: 10.1007/s11705-009-0087-7. 